\title{
PKM Alat Mesin Peneacah Rumput Untuk Pengembangaternak Masyarakat Mandiri Dan Ekonomis
}

\author{
Muhammad Abdus Shomadי, Rinasa Agistiya 2 \\ 1. Prodi. Teknik Mesin Vokasi Universitas Muhammadiyah Yogyakarta \\ 2 Prodi. Teknik Mesin Vokasi Universitas Muhammadiyah Yogyakarta \\ Jalan Brawijaya Tamantirto, Kasihan, Bantul, Daerah Istimewa Yogyakarta 55183 \\ Email: abdusshomad@umy.ac.id \\ DOI: $10.18196 / \mathrm{ppm} .32 .210$
}

\begin{abstract}
Abstrak
Sasaran program PKM ini adalah kelompok masyarakat usaha ternak yang tergabung dalam Laboratorium Kampung Ternak Jogja (LKTJ) se-Kota Yogyakara. Tujuan program ini adalah untuk mengembangkan ternak masyarakat yang mandiri secara ekonomi.Mitra usaha dalam program ini adalah kelompok ternak dari gabungan para peternak yang diberi wadah "Kampung Ternak Jogja" yang merupakan inisiasi dari Sarjana Membangun Desa. Sebagai bentuk tanggung jawab agrobisinis, khsususnya kepada para peternak dalam pengembangan usaha budi daya peternakan dan pemertahankan kelompok ternak yang ada di Kota Yogyakarta. Perkembangan jumlah ternak dari tahun 2015 hingga 2019 adalah domba dengan persentasi kenaikan $200 \%$ dan sapi 100\%. Dengan kenaikan jumlah ternak yang signifikan tersebut diperlukan sebuah alat yang dapat digunakan penyediaan pakan ternak. Permasalahan yang dihadapi oleh mitra adalah 1) belum tersedianya alat pencacah pakan ternak, 2) peralatan yang digunakan pengadaan pakan masih manual dan terbatas, 3) banyaknya jumlah ternak (kambing, lembu-domba) yang semakin bertambah.Dengan kondisi seperti tersebut di atas, program yang kami usulkan sebagai solusi adalahi) mengadakan peralatan proses produksi pakan ternak yang lebih memadai, 2) pengemasan stok pakan (packing) yang lebih baik, 3) menambah variasi inovasi produk, 4) memperbaiki proses pola pengolahan pakan ternak, 5) efisinsi waktu tenaga pemberi pakan ternak. Program ini diharapkan mampu memfasilitasi perkembangan usaha mitra untuk kemudian mampu memberikan multiplier effek bagi usaha sejenis dan usaha lain yang terkait (bermitra).
\end{abstract}

Kata Kunci : Mesin Pencacah Rumput, Pakan Ternak, Laboratorium Ternak Jogja

\section{Pendahuluan}

Kampung Ternak Jogja merupakan inisiasi dari Sarjana Membangun Desa. Wirausaha Pendamping Yogyakarta sebagai langkah integrasi antarbeberapa kelompok ternak di Kota Yogyakarta. Perkumpulan ini merupakan konsep perkumpulan kelompok ternak yang ada di kampung-kampung di Kota Yogyakarta. Yogyakarta yang identik dengan perkampungan menjadi latar belakang penamaan perkumpulan ini menjadi Kampung Ternak Jogja. Konsep Kampung Ternak Jogja ini awal mulanya digagas pada awal tahun 2014. Sebagai bentuk tanggung jawab agrobisinis khsususnya kepada para peternak dalam pengembangan usaha budi daya peternakan dan pemertahankan kelompok ternak yang ada di Kota Yogyakarta.( Liu, F. N.) (2018)

Seiring berjalannya waktu, pada tahun 2015 kami mendirikan laboratorium Kampung Ternak Jogja sebagai tempat observasi, ujicoba ternak, dan percobaan pembuatan pakan yang kemudian hasilnya disampaikan di kelompok ternak yang tergabung di Kampung Ternak Jogja. Oleh karena itu, laboratorium Kampung Ternak Jogja sampai saat ini terus bergerak di bidang agrobisnis. Selain menjual produk ternaknya, Kampung Ternak Jogja juga sebagai media langsung penyambung antara user dengan peternak di kelompok ternak yang tergabung di Kampung Ternak Jogja. Sejak tahun 2015 laboratorium Kampung Ternak Jogja bersama Kelompok ternak di Kampung Ternak Jogja menyediakan ternak-ternak berkualitas untuk kurban yang diharapkan dapat menjadi barokah bagi penyedia ternak dan shohibul kurban yang membelinya. Selaras dengan menyongsong hari Idhul Adha (Idhul Kurban), untuk menyediakan 
kebutuhan hewan kurban masyarakat Daerah Istimewa Yogyakarta, Kampung Ternak Jogja akan menjadi salah satu supplier hewan kurban yang berkompeten dan profesional dalam memenuhi kebutuhan tersebut. Kebutuhan hewan kurban mengalami peningkatan tiap tahunnya. Hal ini berbanding lurus dengan kesadaran masyarakat untuk berkurban yang terus meningkat. (Sari, L. P., Erina, E., \& Darniati, D). (2017)

Jarak antara kampus UMY dengan mitra kurang lebih $5 \mathrm{~km}$. Kota Yogyakarta merupakan kota dengan luas $32,5 \mathrm{~km}^{2}$, cukup sempit dibandingkan kota-kota besar lainnya. Kota Yogyakarta diapit oleh dua kabupaten besar ,yaitu Kabupaten Sleman dan Kabupaten Bantul sehingga tidak menyurutkan masyarakat di Kota Yogyakarta untuk mengembangkan lahannya menjadi lahan produktif peternakan dan pertanian. Lahan yang dimanfaatkan masyarakat Kota Yogyakarta untuk peternakan kebanyakan berada di beberapa titik, antara lain Kecamatan Tegalrejo, Kotagede, dan Umbulharjo. Sementara titik pertanian, khususnya hortikultura, sebagian tersebar di seluruh kecamtatan di Kota Yogyakarta dengan memanfaatkan lahan yang tersedia.

Kampung Ternak Jogja merupakan gabungan kelompok ternak se-Kota Yogyakarta yang terdiri atas kelompok ternak sapi, domba kambing, dan ayam. Adapun laboratorium Kampung Ternak Jogja merupakan hasil desain bersama sebagai lokasi pembelajaran dari peternak yang tergabung di Kampung Ternak Jogja selain sebagai mitra dalam pengembangan kelompok ternak.

Tantangan para peternak di Kota Yogyakarta cukup berat terkait dengan lingkungan sekitar. Kondisi pemukiman yang sudah padat memunculkan berbagai macam keluhan dari masyarakat sekitar. Kondisi ini memang dilematis karena para peternak di Kota Yogyakarta masih mengandalkan penghasilan salah satunya dari hasil ternaknya. Sebagian besar peternak Kota Yogyakarta adalah masyarakat ekonomi menegah ke bawah dengan pekerjaan serabutan. Selain itu, pemasaran yang kemudian menjadi permasalahan di peternak-peternak Kota Yogyakarta juga menjadi permasalahan inti, tetapi konsep mitra dan usaha berjamaah mencoba dikembangkan untuk mengatasi permasalahan pemasaran ini.

\section{Metode Pelaksanaan}

Pemecahan permasalahan yang dilakukan di laboratorium Ternak Jogja adalah dengan pendekatan bersama-sama. Adapun perinciannya sebagai berikut.

a. Langkah-langkah metode pelaksanaan pengabdian masyarakat pkm alat mesin pencacah rumput untuk pengembanga ternak masyarakat mandiri dan ekonomis tertera pada gambar 1

Program kegiatan ini dilaksanakan dengan beberapa metode, antara lain

a. Observasi Lingkungan kandang

Observasi dilakukan di kandang lab. Ternak Jogja yang terletak di Jalan Bantul km 4,5 Dongkelan RT 10, Panggungharjo, Sewon, Bantul, DIY. Pelaksanaan dilakukan dengan cara wawancara dengan ketua pengelola dan segenap anggota kelompok ternak serta melihat kondisi lapangan secara langsung. Pemetaan ini untuk memperjelas keadaan dan karakteristik kondisi lingkungan kendang ternak terkait kebutuhan alat pemotong rumpu. Pemetaan ini dapat dijadikan sebagai acuan untuk menentukan langkah selanjutnya. (Sukamta, S., Shomad, M. A., \& Wisnujati, A.) (2017) 


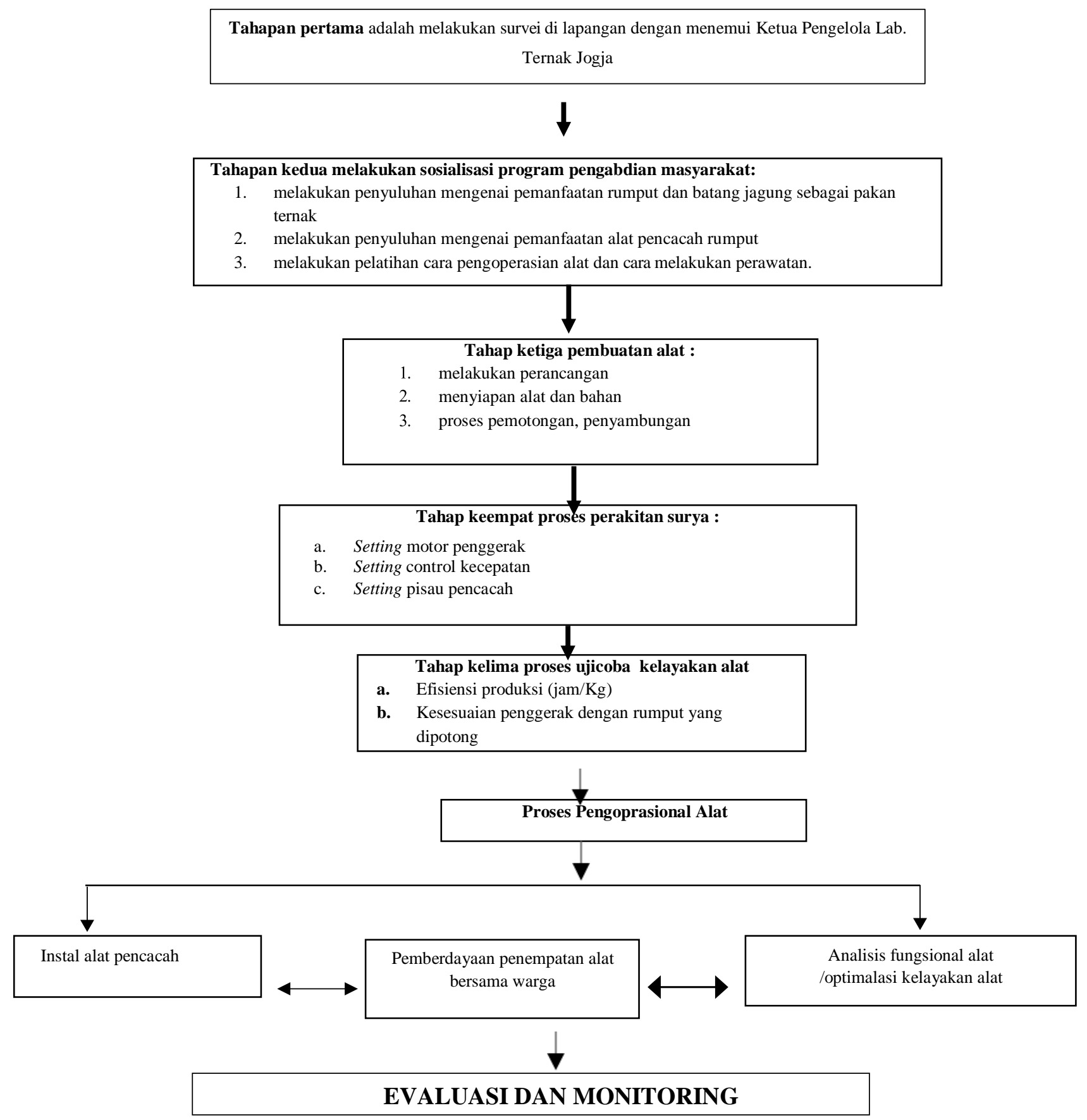

Gambar 1. Langkah-langkah Penerapan Pengabdian Masyarakat

b. Sosialisasi

Sebelum pelaksanaan seluruh rangkain kegiatan pengabdian masyarakat ini dimulai, perlu diadakan sosialisasi mengenai program ini pada Ketua Pengelola Lab. Kampung Ternak, anggota pengelola, serta masyarakat. Tujuan kegiatan ini adalah agar masyarakat memahami program tersebut dan tidak terjadi kesalahpahaman dalam pelaksanaan program. Selain itu, sosialisasi juga berfungsi untuk menggali lebih dalam mengenai permasalahan yang dialami masyarakat dan solusi yang dibutuhkan. Dengan begitu, diharapkan program pengabdian masyarakat ini dapat menghasilkan luaran yang sesuai dengan keinginan dan kebutuhan masyarakat. (Nisa, N. I. F., Aminudin, A., \& Fahrudi, Y. A). (2019) 


\section{c. Lokasi Pelaksanaan}

Lokasi pelaksanan program ini adalah di wilayah Panggungharjo di Jalan Bantul km 4,5, Dongkelan RT 10, Panggungharjo, Sewon, Bantul, DIY, Kabupaten Bantul, Daerah Istimewa Yogyakarta.

\section{d. Pelaksanaan Program}

Rangkaian kegiatan program pengabdian masyarakat yang akan dilakukan meliputi beberapa tahap:

1. Perhitungan kebutuhan pakan ternak perhari

Pada kegiatan ini dilakukan perhitungan kebutuhan pakan ternak berdasarkan jumlah hewan dan tenaga pemberi pakan. Setelah melakukan survei dilapangan dan berdasarkan analisis situasi, dipastikan kapasitas mesin pencacah. (Fathurohman, F., Mukminah, N., Purwasih, R., Sobari, E., Rahayu, W. E., Romalasari, A., \& Destiana, I. D.,) (2018)

2. Pelaksanaan Pembuatan alat pencacah rumput pakan ternak ini melibatkan mahasiswa tingkat akhir yang sedang melaksanakan tugas akhir (TA). Hal ini bertujuan agar ada keterlibatan mahasiswa dalam kegiatan pengabdian masyarakat. (Syahrir, M., \& Hasan, I.) (2020)

3. Evaluasi dan Tindak lanjut

Evaluasi dilakukan untuk mengetahui seberapa efektif program ini dan seberapa besar manfaat atau kontribusinya kepada kelompok ternak di lab. Kamung ternak jogja dan masyarakat. Tindak lanjut program ini sangat diperlukan untuk menjamin keberlangsungan program sebagai perwujudan solusi yang tuntas dalam penanganan masalah di lokasi pengabdian saat ini.

\section{Hasil dan Pembahasan}

A. Hasil Pengabdian Masyarakat

\section{Melakukan survai lapangan}

Kegiatan pengabdian masyarakat ini dilaksanakan di Pedukuhan Panggungharjo, Kecamatan Sewon, Kabupaten Bantul, Yogyakarta. Seperti ditunjukkan pada gambar 2 dan gambar 3, kegiatan diawali dengan survei lokasi. Berdasarkan hasil survei tersebut, didapatkan informasi mengenai pentingnya kebutuhan alat pencacah rumput yang diperlukan.

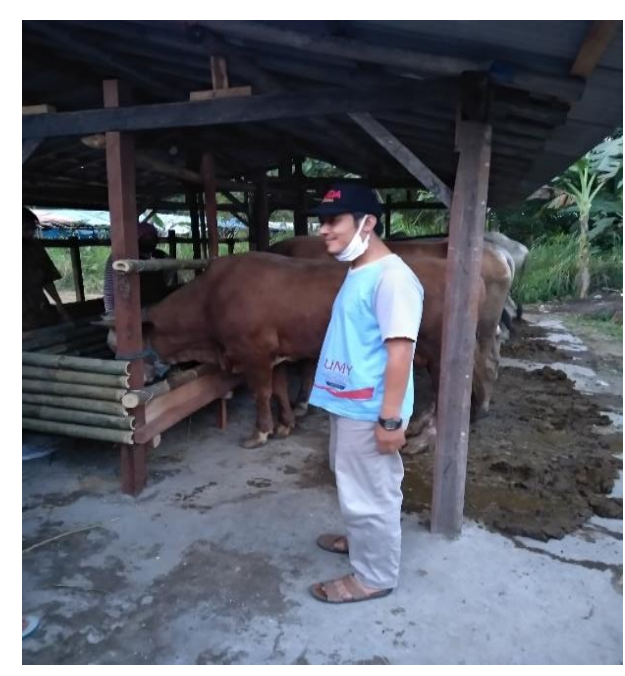

Gambar 2. Survei Lokasi

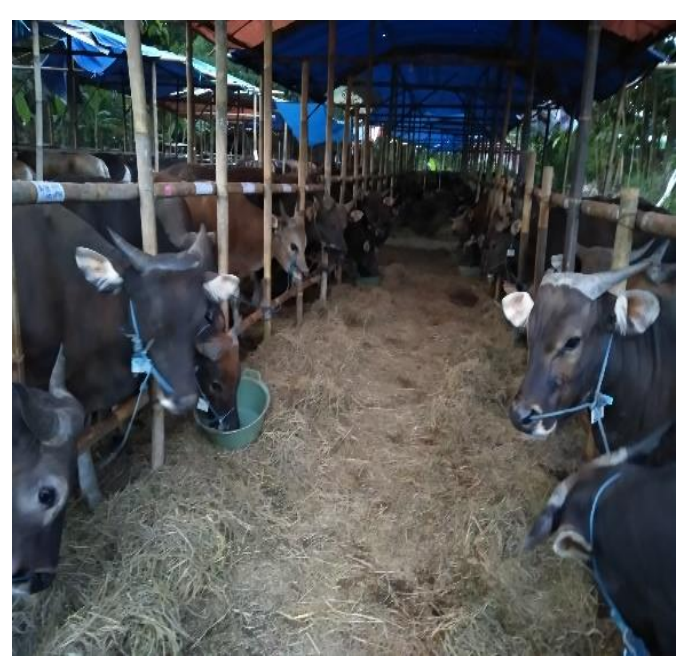

Gambar 3. Situasi Kandang 
2. Melakukan uji alat pencacah rumput

Pelaksanaan pengujian kelayakan ini mempunyai tujuan, yaitu untuk mengentahui fungsional alat dan mengetahui kapasitas alat tersebut dapat bekerja secara optimal. Pengujian alat ini dilaksanakan bersama pengelola Kelompok Pernak dan Laboran D-3 Teknologi Mesin UMY seperti yang terlihat pada gambar 4 dan 5. (Ilham, W. (2019).

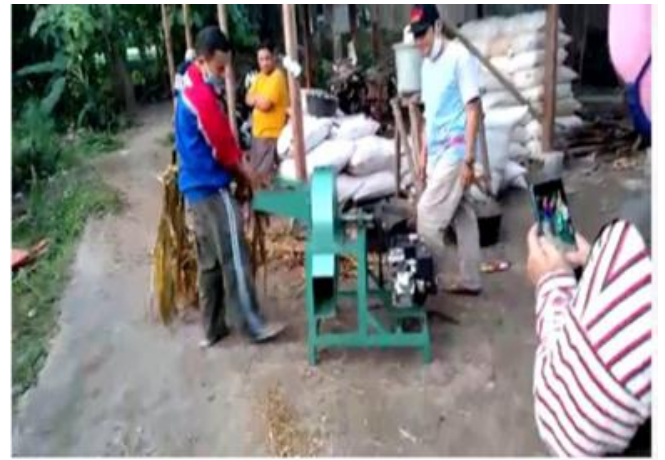

Gambar 4. Melakukan Uji Alat

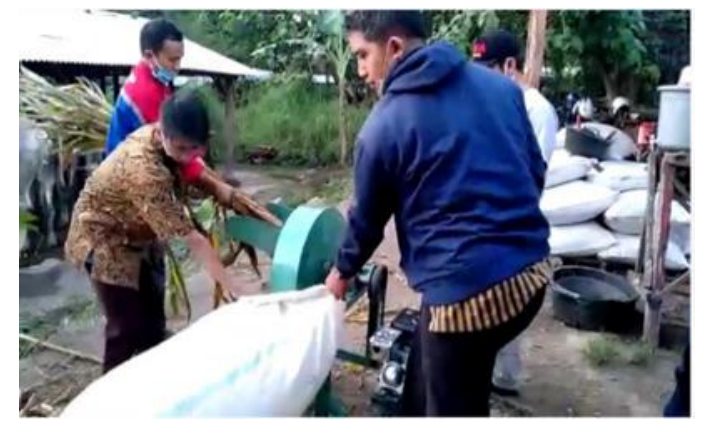

Gambar 5. Uji Fungsional Kapasitas Produksi

3. Serah terima Alat

Dari serangkaian proses kegiatan pelaksanaan pengabdian ini, diakhiri dengan penyerahan alat (barang) kepada Ketua Pengelola Laboratorium Kampung Ternak Jogja, Bapak dr.Imam Abror.

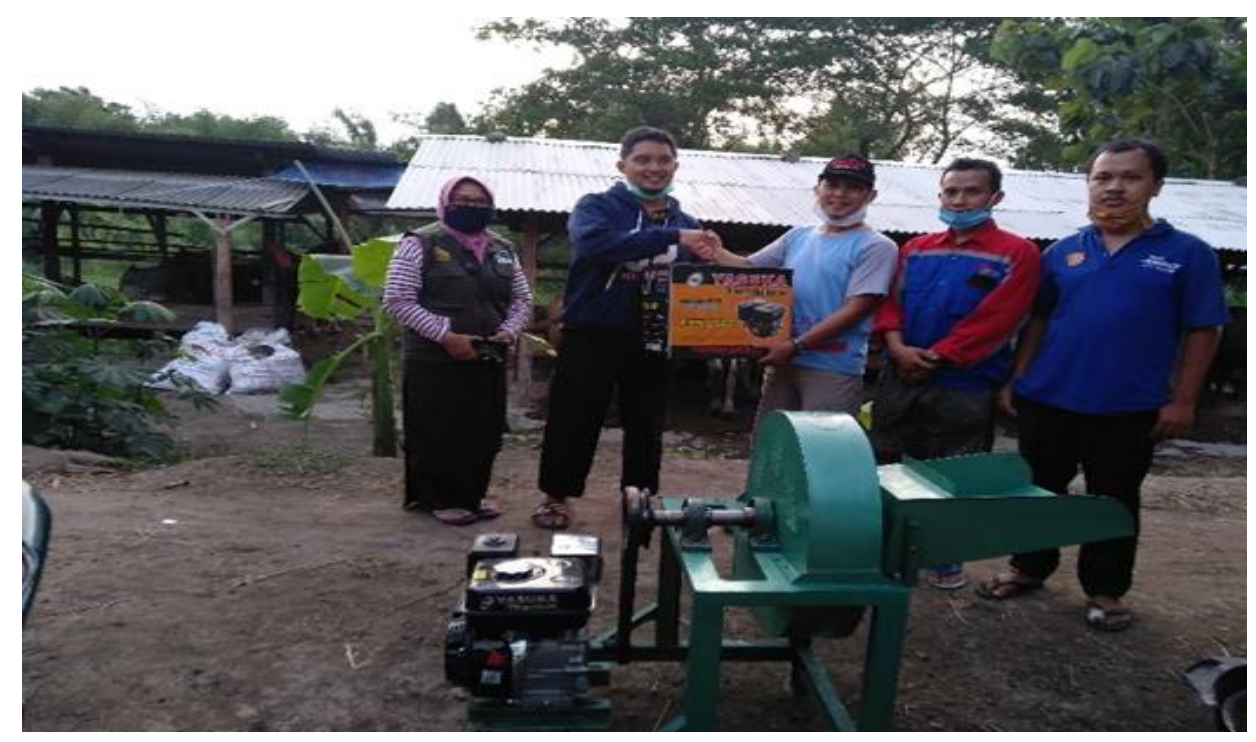

Gambar 6. Serah terima alat Pencacah Rumput

Dari gambar 7 dapat dilihat ukuran batang jagung yang telah dipotong dengan alat pencacah rumput pakan ternak sampai mempunyai ukuran yang kecil sehingga memudahkan sapi untuk memakan dan mengunyahnya dengan mudah. (Suwarta, F. X., \& Purwani, T. (2018). 


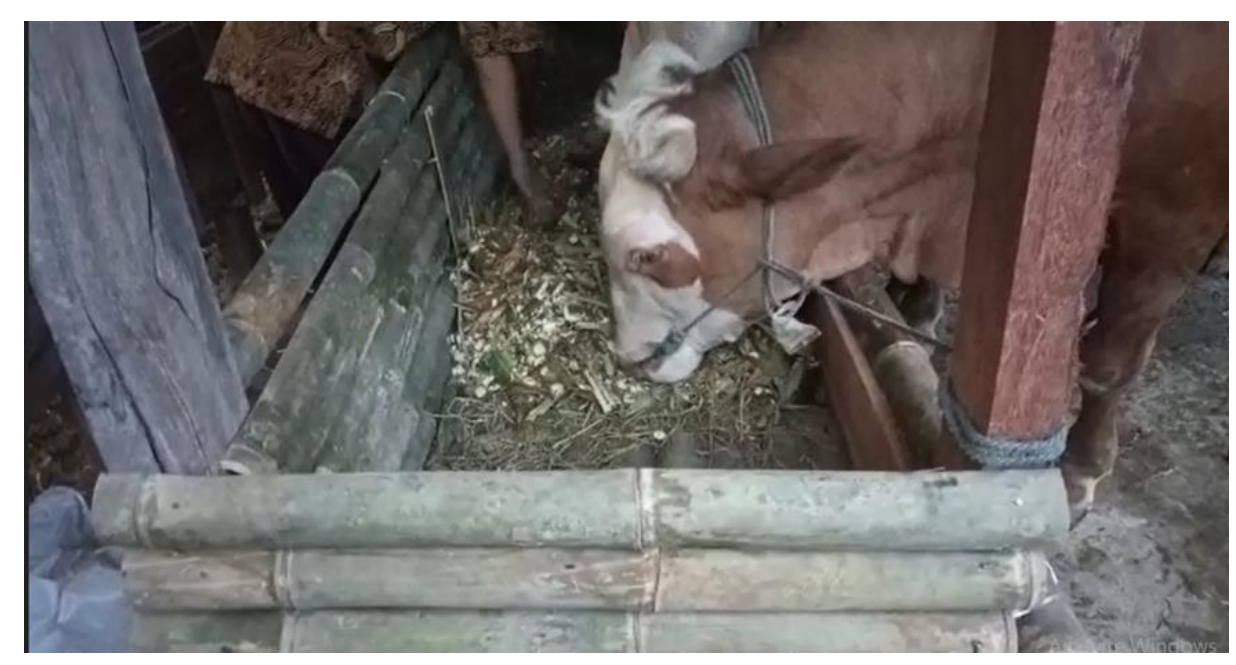

Gambar 7. Uji coba hasil produksi alat pencacah

\section{Prinsip Kerja Alat Pencacah Rumpu untuk Pakan Ternak}

Alat ini merupakan mesin serbaguna untuk perajang hijauan atau rumput yang berbatang, khususnya digunakan untuk merajang rumput pakan ternak. Pencacahan ini dimaksudkan untuk mempermudah ternak dalam memakan,di samping juga untuk memperirit rumput. Mesin pencacah rumput pakan ternak hasil modifikasi ini menggunakan motor listrik sebagai sumber tenaga penggerak. Mesin ini mempunyai sistem transmisi tunggal yang berupa sepasang pulley dengan perantara $v$-belt. Saat motor listrik dinyalakan, putaran motor listrik akan langsung ditransmisikan ke pulley 1 yang dipasang seporos dengan motor listrik. Dari pulley 1, putaran akan ditransmisikan ke pulley 2 melalui perantara v-belt, kemudian pulley 2 berputar, poros yang 9 berhubungan dengan pulley akan berputar sekaligus memutar pisau perajang. Hal tersebut disebabkan pisau perajang dipasang seporos dengan pulley 2. Meski terkesan memiliki fungsi yang sederhana, tetapi mesin berperan cukup besar dalam proses pencacahan. Mesin pencacah rumput ini memiliki beberapa bagian utama, seperti motor penggerak, poros, casing, sistem transmisi, dan pisau perajang seperti terlihat pada gambar 10 .

Alat pencacah rumput ini merupakan sebuah alat yang berfungsi untuk membantu pencacahan rumput bagi peternak sapi. Mesin ini memiliki berbagai tuntutan yang harus dipenuhi sehingga nantinya mesin ini dapat diterima dan digunakan untuk memenuhi segala kebutuhan pengguna. Sebagian besar masalah atau kegagalan desain disebabkan kurang jelasnya kriteria tuntutan pemakai. Alasan utama penolakan desain dari konsumen adalah faktor investasi atau ekonomi yang tidak sepadan. Oleh karena itu, diperlukan cara khusus sebagai langkah awal pengembangan desain dengan mempelajari tuntutan produk dari pemakai. Perancangan mesin pencacah rumput ini didasarkan pada kontruksi dan sistem transmisi yang sederhana yang mampu memotong rumput dengan waktu kurang lebih 15 menit dan menghasilkan cacahan 150$200 \mathrm{~kg}$. Selain itu, faktor keamanan harus diperhatikan dan perawatanya pun mudah.( Sugiyanto, D., Susanto, H., Asbanu, H., \& Saputro, A. (2020) 


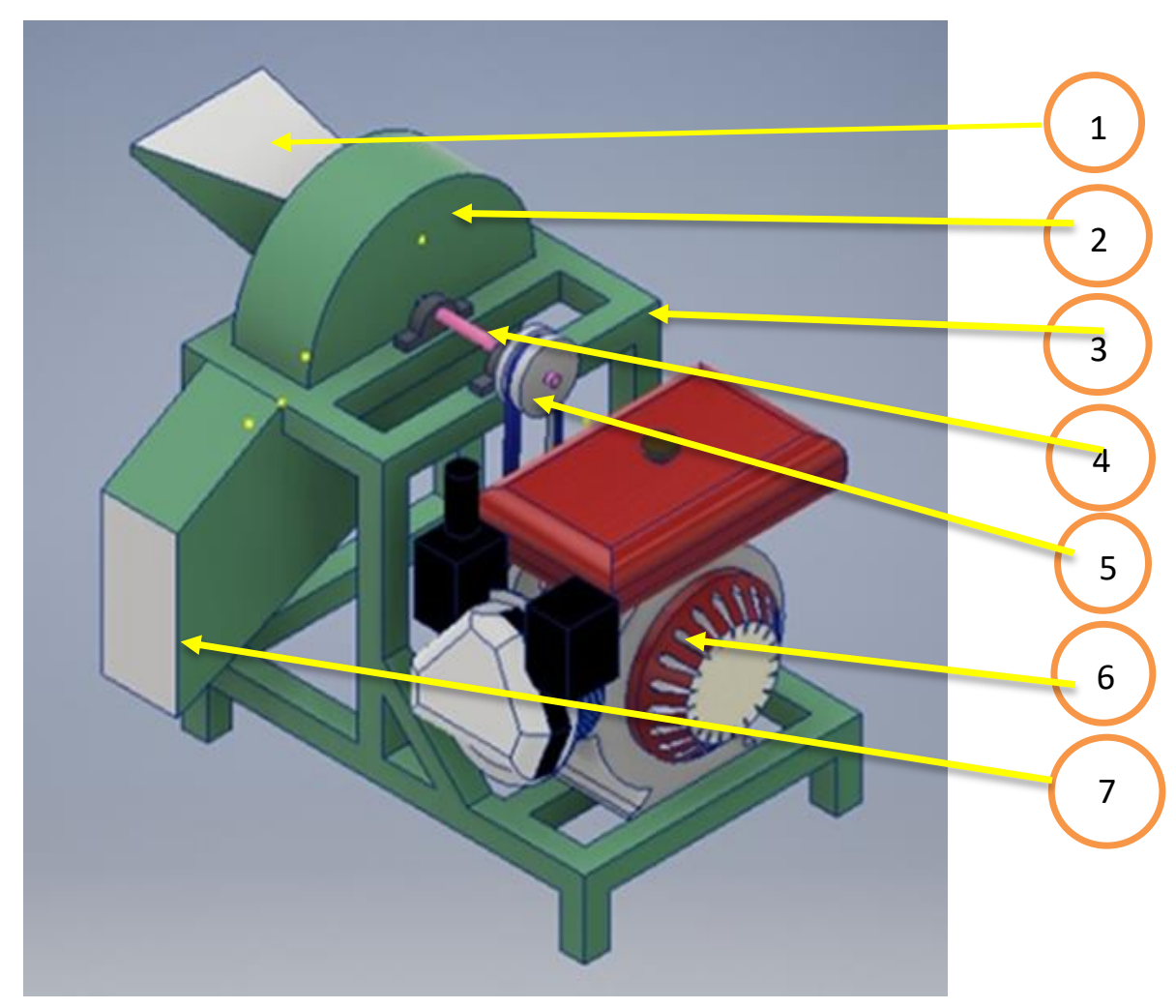

Gambar. 10 Alat Pencacah Rumput Ternak

\section{Keterangan Gambar :}

1. Cerobong masuk rumput

2. Pelindung pisau

3. Rangka

4. Poros

5. Pully

6. Motor Penggerak

7. Cerobong keluar rumput

\section{Realisasi Alat}

Realisasi alat ditunjukkan pada gambar 7 terlihat penyerahan dari ketua Program Pengabdian Masyarakat yang diserahkan oleh ketua pengelola kelompok ternak yaitu satu set alat / mesin pencacah rumput kepada ketua pengelola kelompok ternak yang terdiri: 1 penggerak mesin disel 7HP, 1 set kerangkat yang sudah dilengkapi dengan penunjang lainnya. Realisasi alat pencacah ternak menunjukkan bahwa Program Pengabdian Masyarakat Kemitraan (PKM) memberikan solusi dari masalah yang ada, berkontribusi memberikan satu unit alat mencacah rumput pakan ternak untuk pengelola kelompok ternak di lab, kampung Ternak Jogja yang beralamat di Jln Bantul Panggungharjo Sewon Bantul yang awalnya tidak ada alat/mesin untuk merajang rumput 
pakan ternak atau masih menggunakan sistem manual dan dari hasil survei yang dilakukan oleh tim pengabdi maka untuk mengefektikan waktu dalam proses membuat pakan ternak menunjang pembuatan pakan ternak dengan cepat dan efisensi waktu. Dengan adanya alat tersebut maka proses pemberian pakan lebih cepat dan membuat ternak-ternak lebih lahab dalam memakan rumput karena ukuran rumput menjadi lebih kecih dan mudah untuk dimakan

\section{Simpulan}

Pelaksanaan kegiatan Pengabdian Masyarakat Kemitraan (PKM) telah memberikan manfaat positif, terutama dalam kerangka efektifitas proses pembuatan pakan ternak di kelompok ternah yang di kelola oleh laboratorium Kampung Ternak Jogja. Hal tersebut dilakukan melalui penggunaan alat pencacah rumput pakan ternak. Dengan memperkecil ukuran rumput batang hijau, sapi dengan mudah bisa memakannya.

\section{Ucapan Terima Kasih}

Keberhasilan pelaksanaan kegiatan program pengabdian masyarakat (PKM) merupakan hasil dukungan, kerja sama dan dorongan berbagai pihak. Untuk itu, selaku tim pelaksana, kami menyampaikan terima kasih dan penghargaan yang setinggi-tingginya kepada LP3M UMY dan mitra yang selama kegiatan memberikan dukungan yang positif, baik material maupun nonmaterial.

\section{Daftar Pustaka}

Ari, L. P., Erina, E., \& Darniati, D. (2017). ISOLASI Escherichia coli dan Salmonella sp Pada Telur Ayam Kampung Yang Gagal Menetas Di Laboratorium Lapangan Peternakan Universitas Syiah Kuala. Jurnal Ilmiah Mahasiswa Veteriner, 1(3), 513-520.

Destiana, I. D. (2018,October). Analisis Kelayakan Usaha Agroindustri Pakan Ternak Komplit (Feed Complete): Studi Kasus Di Kabupaten Subang. In Prosiding Industrial Research Workshop and National Seminar (Vol. 9, pp. 488-492).

Fathurohman, F., Mukminah, N., Purwasih, R., Sobari, E., Rahayu, W. E., Romalasari, A., \& Syahrir, M., \& Hasan, I. (2020). Pembuatan Alat Pencacah Rumput Semi Otomatis. Teknik Mesin"

TEKNOLOGI", 20(1 Okt).

ILHAM, W. (2019). Perancangan Alat Pencacah Rumput Gajah Dengan Pisau Lengkung

Kapasitas $11 \mathrm{Kg} / \mathrm{Jam}$ (Doctoral dissertation, Universitas Muhammadiyah Ponorogo)

Liu, F. N. (2018). Strategi Pengembangan Usaha Penggemukan Ternak Sapi Potong di Kelompok

Tani Nekmese di Desa Usapinonot Kecamatan Insana Barat. AGRIMOR, 3(4), 58-60.

Nisa, N. I. F., Aminudin, A., \& Fahrudi, Y. A. (2019). Aplikasi Mesin Pencacah Pakan Ternak Serbaguna Sebagai Upaya Mengurangi Pengolahan Pakan Ternak Secara

Konvensional. JAST: Jurnal Aplikasi Sains dan Teknologi, 3(1), 43-49

Sukamta, S., Shomad, M. A., \& Wisnujati, A. (2017). Pengelolaan limbah ternak sapi menjadi pupuk organic komersial di Dusun Kalipucang, Bangunjiwo, Bantul,

Yogyakarta. BERDIKARI: Jurnal Inovasi dan Penerapan Ipteks, 5(1), 1-10. 
Suwarta, F. X., \& Purwani, T. (2018). Penerapan Integrasi Tanaman Ternak Lahan Kering Berbasis Usaha Ternak Kambing Di Kabupaten Gunung Kidul. SENADIMAS. 